\title{
The Initial Economic Impact of Brexit: An Update to Early December 2016
}

\begin{abstract}
On June 23, 2016, the United Kingdom's vote to leave the European Union came amid widespread professional forecasts of financial volatility, a likely growth slowdown for the United Kingdom, and potential spillovers to the rest of the EU and even to countries outside the EU's Single Market. After a relatively brief interlude of jitters, however, equity markets recovered and interbank stains were avoided (albeit with central bank support). The main durable financial market effect has been a substantial depreciation of the pound sterling. At the same time, economic signals from the U.K. economy have been mixed, with fairly robust consumer spending and exports sustaining the economy so far. The shape of the ultimate terms of trade between Britain and its former EU partners remains unclear, however, and the uncertainty seems likely to weigh on future investment and hiring. It is unlikely that substantial U.K. control over the free movement of EU persons across its borders - a main objective of the pro-Brexit campaign—will prove compatible with anything near full access to the Single Market. Moreover, any eventual loss of access to the Single Market, including for financial services, will very likely reduce the United Kingdom's steady-state income.
\end{abstract}

o understand the consequences of Brexit for the United Kingdom and world economies, it is useful to start off with an overview of the events after the June 23, 2016, referendum and immediate prospects. I was in Europe the day of the Brexit vote - and awake much of the following night. Mercifully, a weekend intervened after the first full day of market reaction on Friday, June 24, 2016. The next Monday, apprehension among the assembled policymakers was palpable when the European Central Bank's annual policy conference opened in Sintra, Portugal. Federal Reserve chair Janet Yellen and Bank of England governor Mark Carney had both canceled their appearances. The planned final policy panel was a hastily organized replacement-devoted, naturally, to Brexit. 
Figure 1. The Performance of U.K. Equity Markets and Bonds, 2016

Equity markets

Index (June 23, 2016=100)

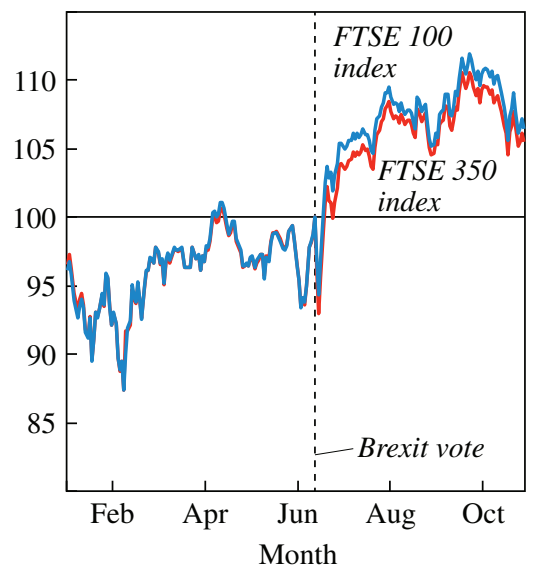

10-year government bond yields

Percent

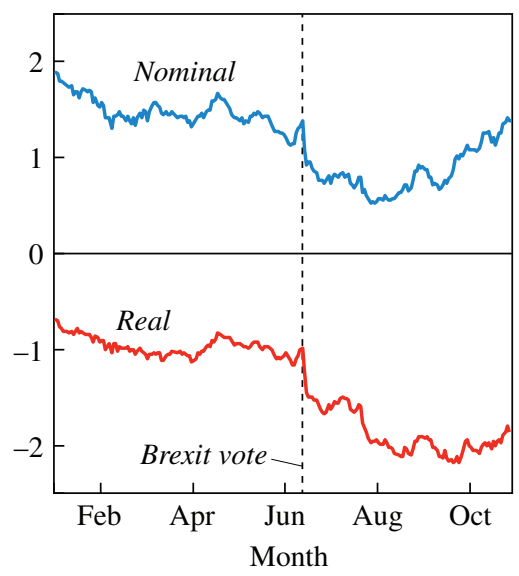

\section{Corporate bond yields}

Percent

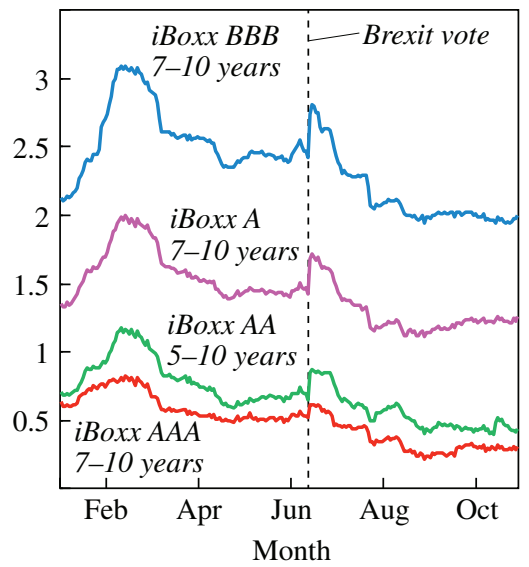

Sources: Haver Analytics; IMF staff estimates.

As shown in figure 1, equity markets fell and corporate bond interest rates rose on June 24, 2016, as markets began to price in the unexpected result of the U.K. referendum. Equity markets recovered quite quickly. Corporate bond yields dropped after the initial upward spike, and government bond yields-especially those of gilts-dropped dramatically worldwide in real terms. Contrary to this outcome, some negative pre-Brexit 
scenarios had assumed persistent increases in both gilt and corporate rates. Globally, asset markets also proved notably resilient; contradicting fears, peripheral eurozone sovereign yields remained broadly stable.

As shown in figure 2, economic sentiment, which had been falling for a while before the vote, fell further immediately after the vote; but it has substantially recovered in more recent months. Similarly, Purchasing Managers' Indexes (PMIs) for manufacturing dropped in July, although they have bounced back since August. One of the most durable outcomes is the depreciation of sterling, which—let us not forget—reduces British residents' purchasing power, because it is a big tax on their purchases of foreign goods. Because Brexit will discourage direct investment inflows, Britain's large current account deficit will need to shrink, requiring a depreciation of the pound. Looser monetary policy has also helped push sterling down (while pushing down U.K. interest rates and supporting the economy). Its depreciation accelerated in October 2016, when U.K. prime minister Theresa May signaled that serious negotiations with the European Union would start in the early spring of 2017. Some denial about the reality of Brexit may have evaporated at that point.

Labor market indicators have been pretty steady so far, as shown in figure 3. We do not see any real action after the Brexit vote in terms of employment, but this is no surprise because labor market conditions tend to be a lagging indicator. The conventional wisdom is that British exports are not that responsive to the exchange rate, but export orders did pick up noticeably starting in August after small increases during May and June, perhaps for reasons unrelated to the currency.

More generally, none of these trends is well established yet, other than the exchange rate's, and it is important to keep in mind that relatively few data are available thus far. In this context, a number of forecasters, including the International Monetary Fund, have weighed in on the likely growth outcomes for 2016 and 2017. This diversity is shown in figure 4. Most forecasters downgraded their 2016 GDP projections immediately after the Brexit vote; but more recent updates indicate considerable heterogeneity across forecasters. However, large downward revisions for 2017 GDP forecasts have persisted across most forecasters.

Where are we now? The short-run financial market outcome was much more benign than expected. Many worried what the market impact would be, with some even talking of a reaction similar to when Lehman Brothers collapsed in 2008. Central banks were certainly on high alert; but in the end, the result was good news about the resiliency of financial markets.

Will these favorable effects be reversed? There is no immediate reason to think so. But as we keep emphasizing at the IMF, financial markets could 
Figure 2. U.K. Economic Sentiment, PMIs, and Exchange Rates, 2010-16

Economic sentiment

Index (long-term average $=100$ )

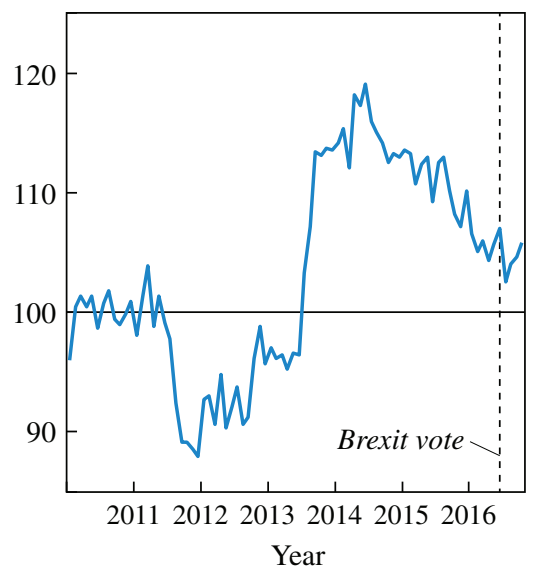

PMIs for construction and services

Index (50+ indicates expansion)

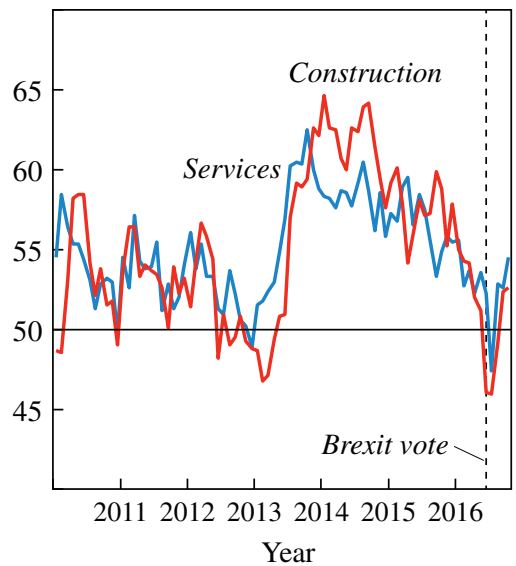

Exchange rates

Nominal effective exchange rate

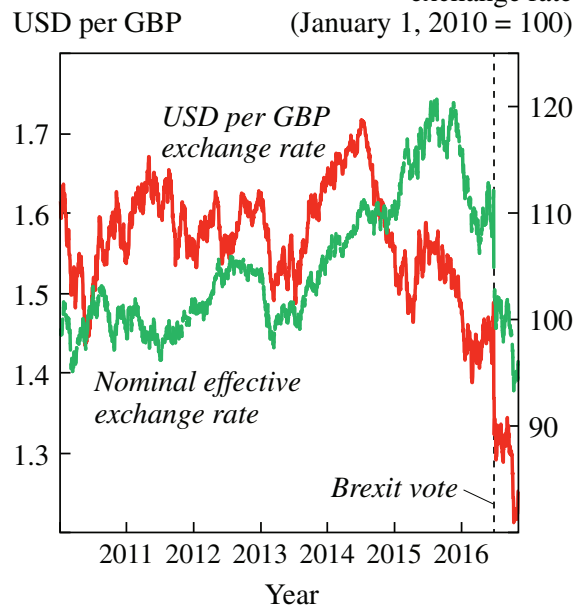

Sources: Haver Analytics; Global Data Source database; IMF staff estimates. 
Figure 3. U.K. Labor Market Indicators and Trade, 2000-16

\section{Labor markets}

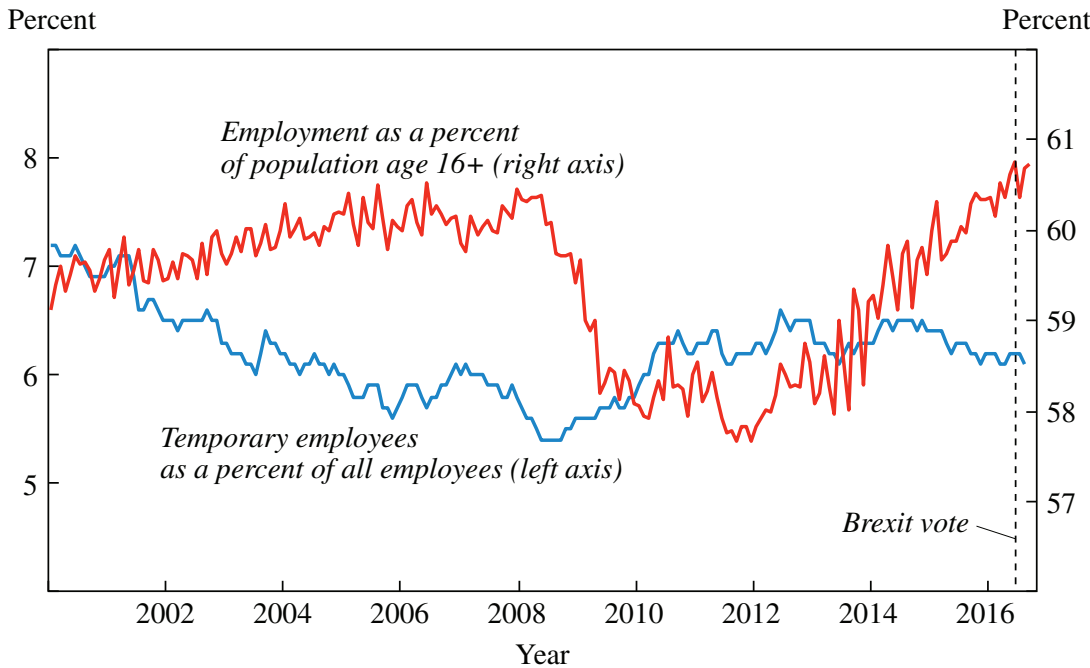

Export orders and sterling real exchange rate

PMI for new export orders

(50+ indicates expansion)

Real effective exchange rate

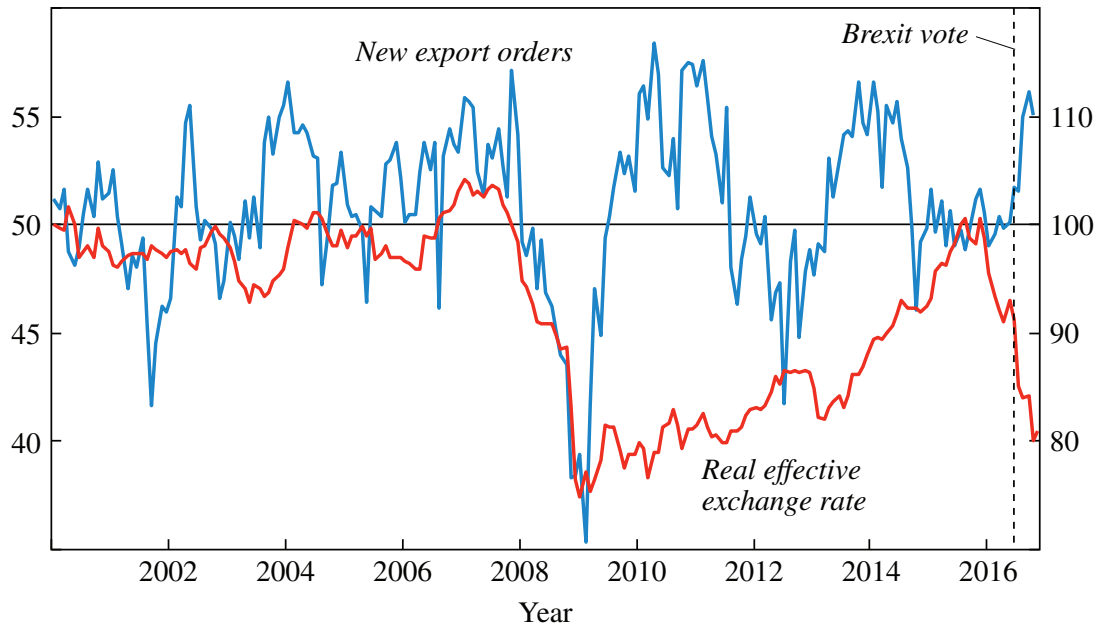

Sources: Haver Analytics; Global Data Source database; IMF staff estimates. 
Figure 4. U.K. GDP Forecast Revisions after the Brexit Vote ${ }^{a}$

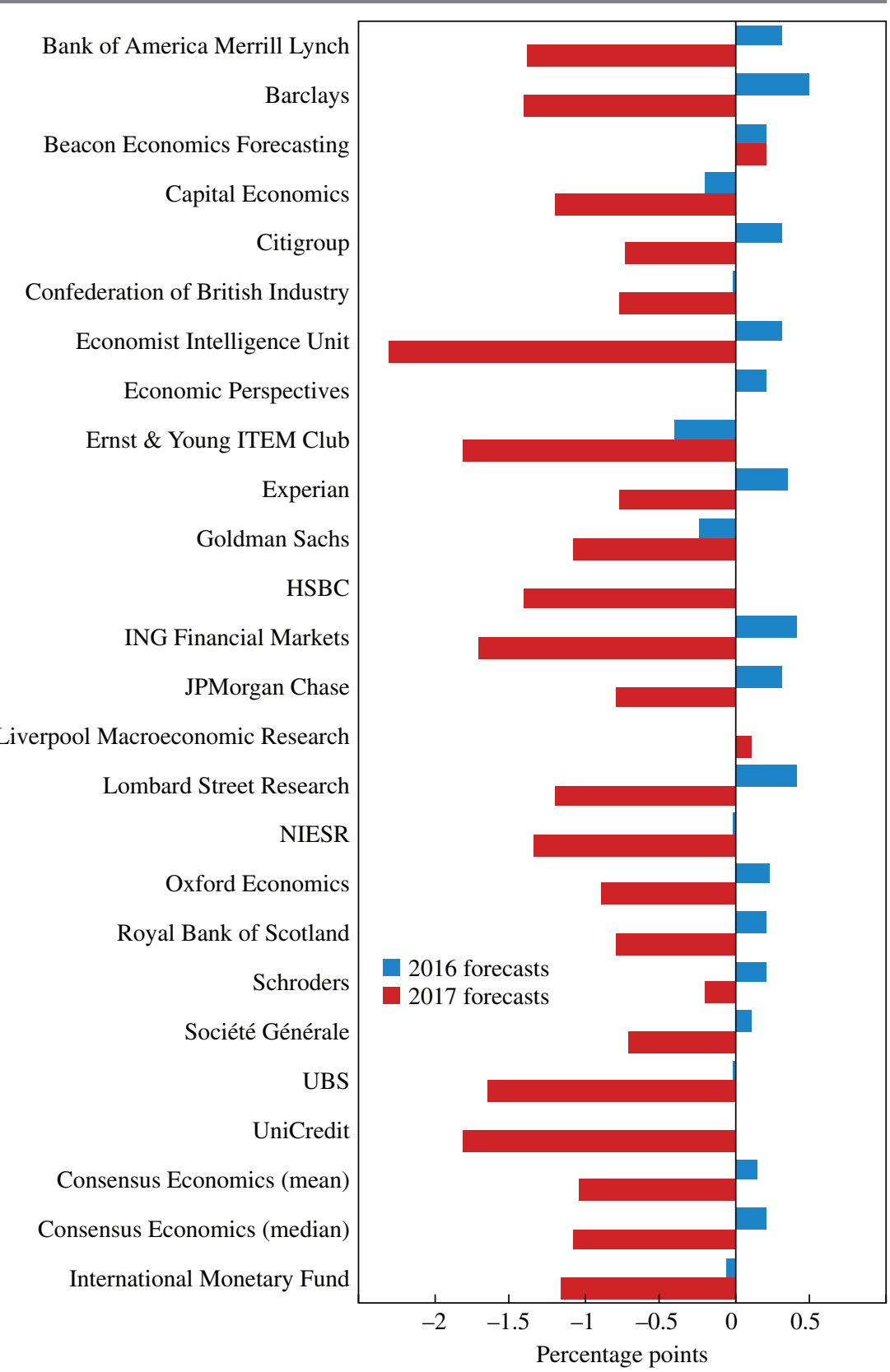

Sources: Consensus Economics; IMF, World Economic Outlook.

a. Revisions are the changes in forecasts between the pre-Brexit vote vintage data and the most recently available vintage data as of November 17, 2016. 
respond very strongly to new negative data if and when they emerge. The exchange rate depreciation has probably helped the United Kingdom, on balance, in terms of increasing competitiveness. Much U.K. foreign debt is denominated in sterling, so depreciation has benefited the country's net international investment position. The Bank of England's support of the economy has, among other benefits, the effect of cushioning the fall in housing prices a bit (including through the exchange rate).

However, there is much uncertainty about what is next. This uncertainty is likely to be prolonged, and could fundamentally affect the allocation and level of investment within the European Union. The effects on the United Kingdom will be strongest, but there could also be effects on the rest of Europe. More recently, the level of global policy uncertainty has increased, especially in the United States since its November 8, 2016, presidential election. Italy's December 4, 2016, referendum rejection of Prime Minister Renzi's electoral reform, coupled with ongoing troubles in the country's banking sector, has added further to the political churn.

Looking toward 2017, Dutch and French elections are coming up, and then a German one. Italy also could see its own, as could Greece. Germany's election will not be resolved before the fall of next year, and it is hard to believe that serious negotiations could happen during ongoing electoral campaigns. Britain's triggering of Article 50 of the European Union's Treaty of Lisbon—which Prime Minister May has promised by April 2017—will, however, start a two-year clock before Britain's EU membership automatically terminates. This Article 50 decision could be subject to parliamentary approval - the government's case that it can proceed without Parliament is still before the United Kingdom's supreme court, as of this writing. But once this clock starts, the bargaining power looks to be skewed toward the EU-27. Given the complexity of finding a mutually acceptable divorce settlement, it seems highly likely that the clock will run out with some interim agreement governing Britain's relationship with the European Union, and with negotiations on a permanent settlement set to continue indefinitely. Such an outcome would perpetuate the current uncertainty, to the detriment of investment and any other economic activity requiring sunk start-up expenditures. These effects will be strongest in the United Kingdom, but also will be felt to some degree on the European continent.

With regard to the structural factors, it is clear that there are going to be big supply-side effects from reallocation of activity within the current European Union in response to the new rules. Many investors have built capacity in the United Kingdom on the premise that they can sell freely into the EU, and that may no longer be true. In some areas-such 
as automobiles-components currently cross the British border with the EU-27 multiple times in the course of production. This could become much harder with the United Kingdom out of the EU. Some in the United Kingdom speak about maintaining access to the Single Market, but there will be a very harsh trade-off between such access and allowing free migration from the rest of the EU. The costs to Britain's financial sector will be especially severe. U.K. foreign secretary Boris Johnson has asserted that Britain will keep its crucial EU financial passport- "We'll have our cake and eat it." This seems exceedingly unlikely, although there is now speculation about Britain paying a fee to maintain the passport. If so, the price will likely be exorbitant.

One perverse effect we could see is that, in a prolonged negotiation scenario, immigrants actually start rushing to the United Kingdom in advance of the new regime just because they do not think they will be ejected after negotiations end. And so we could actually see a surge in labor supply, which would support output growth in the short run.

In the papers that follow, John Van Reenen and Thomas Philippon have much to say about the politics of Brexit, but an obvious point is that too good a deal for the United Kingdom would further encourage the EU's centrifugal forces; and so EU negotiators will be tough, for if the United Kingdom finishes with a highly favorable deal, pressures from other EU memberssome backed by referendum threats - could prove hard to contain.

Could the United Kingdom reconsider? In light of the disarray within the U.K. political system, I find it hard to see how that could happen. At the moment, there is no effective opposition party to the ruling Conservative Party. But the Conservative Party's center of gravity has moved toward Brexit, so who would fight a campaign in support of a new referendum? A coalition of the center has yet to appear, and one seems unlikely in the medium term. It is not clear that even a requirement that Parliament must approve the invocation of Article 50 could or would stop the process.

Outside Britain, the Brexit shock is an urgent wake-up call that multiple arrangements within the European Union are not working well and are not viewed as serving people at a very basic, everyday economic level. Regardless of how the negotiation with the United Kingdom goes, there needs to be serious rethinking about how the EU works, especially within the eurozone. If the EU's leaders cannot deliver, voters are likely to demand national solutions with increasing insistence. 